\title{
On Ostrowski-Mercer inequalities for differentiable convex function
}

Muhammad Aamir Ali $^{1}$, Ifra Bashir Sial ${ }^{2}$, and Hüseyin BUDAK ${ }^{3}$

${ }^{1}$ Nanjing Normal University School of Mathematical Sciences

${ }^{2}$ Jiangsu University

${ }^{3}$ Düzce University

March 13, 2021

\begin{abstract}
In this note, for differentiable convex functions, we prove some new Ostrowski-Mercer inequalities. These inequalities generalize an Ostrowski inequality and related inequalities proved in $[3,5]$. Some applications to special means are also given.
\end{abstract}

\section{Hosted file}

MMAS-3-5-2021.pdf available at https://authorea.com/users/330633/articles/513473-onostrowski-mercer-inequalities-for-differentiable-convex-function 